\title{
Morphology and Structure Properties of Boron-doped Diamond Films Prepared by Hot Cathode Direct Current Plasma Chemical Vapor Deposition
}

\author{
Mengmei PAN ${ }^{1}$, Hongyan PENG ${ }^{1 *}$, Wanbang ZHAO $^{2}$, Hongwei JIANG $^{3}$ \\ ${ }^{1}$ Physics and Electronic Engineering College of Hainan Normal University, Haikou, 571158, PR China \\ ${ }^{2}$ School of Automotive Engineering, Dalian University of Technology, Dalian, 116024, PR China \\ ${ }^{3}$ Mudanjiang Normal College, Mudanjiang 157012, PR China \\ cross $^{\text {ref }}$ http://dx.doi.org/10.5755/j01.ms.22.2.12923
}

Received 20 August 2015; accepted 11 March 2016

\begin{abstract}
Boron-doped diamond (BDD) films were deposited by hot cathode direct current plasma chemical vapor deposition (HCDC-PCVD) according to various mixture ratios of $\mathrm{CH}_{4} / \mathrm{H}_{2} / \mathrm{B}\left(\mathrm{OCH}_{3}\right)_{3}$ gas. The Raman performances and surface morphologies of the BDD films were then characterized by Raman spectroscopy and scanning electron microscopy (SEM). Results indicated that the flow rate of $\mathrm{B}\left(\mathrm{OCH}_{3}\right)_{3}$ had marked effects on the growth characteristics of the produced boron-doped diamond films. The presence and concentration of the doped boron atoms significantly altered both the surface morphologies and structures of the diamond films. With increasing flow rate of $\mathrm{B}\left(\mathrm{OCH}_{3}\right)_{3}$, the crystal grain surfaces became smooth as visible under SEM. The B-doping levels in these films increased from $1.75 \times 10^{19} \mathrm{~cm}^{-3}$ to a maximum of $2.4 \times 10^{21} \mathrm{~cm}^{-3}$, estimated from the Raman spectra.

Keywords: hot cathode direct current PCVD (HCDC-PCVD), boron-doped diamond (BDD) films, structural properties.
\end{abstract}

\section{INTRODUCTION*}

Boron-doped diamond (BDD) possesses unusual physical and chemical properties, such as high hardness, a very wide range of electrochemical potential and low voltammetric background current in an aqueous medium, corrosion stability, et al., that identify it as an interesting material for electrochemical applications $[1,2]$. The electrical behaviour of BDD films varies from insulating, semiconducting to metallic, depending on the doping amount [3]. In addition, the doping of boron can alter the characteristics of the diamond film such as crystal morphology, quality, microstructure, Raman spectrum property and the amount of non-diamond impurities [4].

Though the deposition and properties of BDD films have been discussed by many researchers in microwave plasma assisted chemical vapor deposition (MPCVD) and hot filament chemical vapor deposition (HFCVD) systems $[5,6]$, they were rarely been investigated thoroughly for the deposition in hot cathode direct current plasma chemical vapour deposition (HCDC-PCVD) systems. It is still necessary to study the morphology, structure, bonding behavior and electrochemical characterization of BDD in HCDC-PCVD systems. The simple reason is that the HCDC-PCVD can offer several pronounced advantages such as cost effectiveness, large area, convenient handling, etc., besides more effective decomposition of the feeding gas in HCDC-PCVD [7] as compared to HFCVD and bring about higher boron-doping levels in the films to improve the electrical performance of BDD films. In this work, we prepared BDD films by HCDC-PCVD with various boron dopant concentrations. The effects of boron doping on the structural characteristics of the diamond films were then characterized by SEM and Raman spectroscopy. The B-

\footnotetext{
* Corresponding author. Tel.: 0086-0898-65882863;

fax: 0086-0898-65882863. E-mail address: mdjphy@163.com (H. Peng)
}

doping levels in these films were estimated from the Raman spectra. Some interesting results were presented and discussed.

\section{EXPERIMENTAL DETAILS}

BDD films were deposited on the $\mathrm{p}$ - $\mathrm{Si}$ substrates in a stainless steel chamber of the HCDC-PCVD system; the chamber was evacuated down to $10^{-2} \mathrm{~Pa}$ prior to each deposition. The deposition details of the BDD films were described in previous literature [7]. Briefly, the reactant gas was a mixture of high purity $\mathrm{CH}_{4}$ and $\mathrm{H}_{2}$. Trimethyl borate $\left(\mathrm{B}\left(\mathrm{OCH}_{3}\right)_{3}\right)$ was used as the boron source, introduced into the chamber with an additional line of bubbling hydrogen gas. All deposition processes were conducted at a pressure of $13 \mathrm{kPa}$. The plasma was excited by a DC power supply with a voltage of $700 \mathrm{~V} \sim 800 \mathrm{~V}$ and a current of $8 \sim 10 \mathrm{~A}$. The substrate temperature was maintained at approximately $800{ }^{\circ} \mathrm{C}$. The growth time was 7.5 hour for each sample. The deposition parameters are described in Table 1.

Table 1. Deposition parameters of BDD films

\begin{tabular}{|c|c|c|c|}
\hline Sample & $\mathrm{CH}_{4}, \mathrm{sccm}$ & $\mathrm{H}_{2}, \mathrm{sccm}$ & $\mathrm{B}\left(\mathrm{OCH}_{3}\right)_{3}+\mathrm{H}_{2}, \mathrm{sccm}$ \\
\hline a & 4 & 200 & 0 \\
\hline b & 4 & 200 & 1 \\
\hline c & 4 & 200 & 2 \\
\hline d & 4 & 200 & 5 \\
\hline e & 4 & 200 & 10 \\
\hline f & 4 & 200 & 20 \\
\hline
\end{tabular}

The morphologies of the BDD films were then analyzed by scanning electron microscopy (S-4800, Hitachi, Japan). The Raman properties were characterized by Raman spectrometer (inVia Raman, Renishaw Corporation, UK) over a frequency range of $200 \sim 2000 \mathrm{~cm}^{-1}$ with an argon ion laser with an excitation wavelength of $514.5 \mathrm{~nm}$. 


\section{RESULTS AND DISCUSSION}

The SEM top views of the BDD films are shown in Fig. 1. The images demonstrate highly faceted surfaces with uniform textures. As shown in Fig. 1 a, sample a (the film without boron incorporation) revealed predominant (111) orientation and clear growth steps on the crystal faces. When the boron content in the gas phase increased, the (110) diamond texture increased simultaneously and the growth steps on the crystal faces gradually diminished and finally disappeared, thus indicating that $\mathrm{B}$ atoms introduced into the films provided benefit (110) to directional growth. In general, the deposited CVD films consisted primarily of (111) and (100) facets, depending on the growth velocity ratio of the $\langle 100\rangle$ and $\langle 111\rangle$ directions. It has been previously posited that substrate temperatures higher than $1170 \mathrm{~K}$ benefited the growth in the $\langle 100\rangle$ direction while substrate temperatures lower than or equal to $1070 \mathrm{~K}$ benefited the growth in the $\langle 111\rangle$ direction [8]. Experimental results of HCDC-PCVD were in keeping with that conclusion, considering the substrate temperature of $800{ }^{\circ} \mathrm{C}(1073 \mathrm{~K})$ and the faceted grains which were dominated by the (111) texture as shown in Fig. 1 a. The SEM views of the BDD films shown in Fig. $1 \mathrm{~b}-\mathrm{f}$ demonstrated an increase in the (110) diamond texture with boron content increased in the gas phase, which is in accordance with Bartsch's results [9].

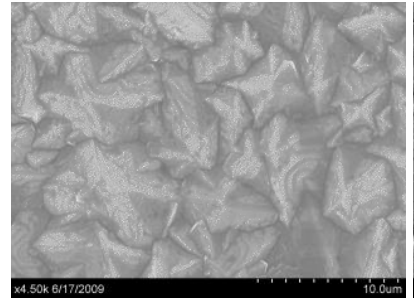

a

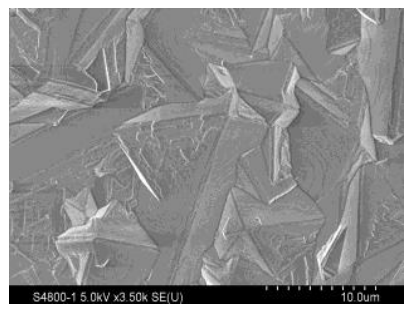

c

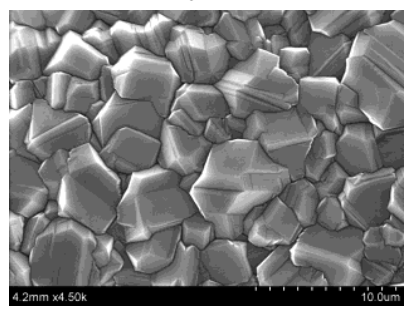

$\mathrm{e}$

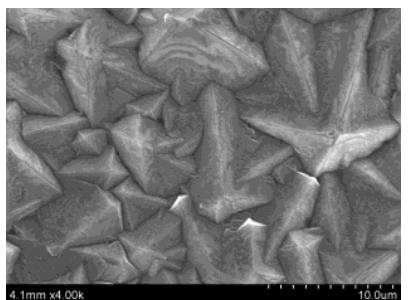

$\mathrm{b}$

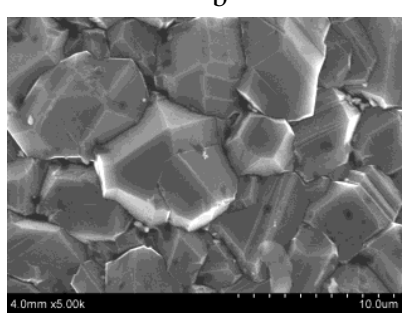

d

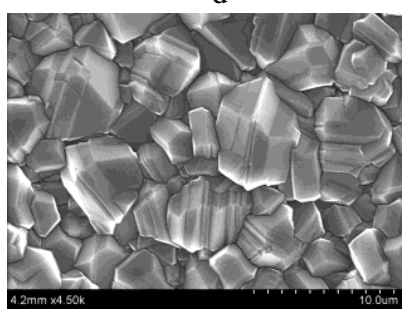

f
Fig. 1. SEM images of BDD films deposited at different B flow rate: $a-0 \mathrm{sccm} ; \quad b-1 \mathrm{sccm} ; \quad \mathrm{c}-2 \mathrm{sccm} ; \quad d-5 \mathrm{sccm}$; e-10 sccm; f-20 sccm

Besides, there were ridges and steps oriented parallel to one other, manifesting twinning bands within the grains intersecting with the surface. The features were especially clear on the samples of e and f, i.e. deposited with high $\mathrm{B}\left(\mathrm{OCH}_{3}\right)_{3}$ flow rate. The results were also observed and researched thoroughly by R.J.Zhang [10], they explained that twinning on the $\{111\}$ planes of diamond needs a very little quantity of energy, so twinning dominanted the feature of the CVD diamond films and also speculated that the strain introduced by the boron atom may be responsible for this.

The grain facets gradually evolved with increasing boron flow rates into symmetrical and smooth structures. The primary grain size ranged from $2 \mu \mathrm{m}$ to $5 \mu \mathrm{m}$ for each sample, and the size was unaltered as the boron flow rate varied from $0 \mathrm{sccm}$ to $20 \mathrm{sccm}$. This is a noted variation from results obtained by J.A.N. Goncalves, et al. [11], who reported decreasing grain size with increasing boron concentrations in BDD films prepared by hot filament chemical vapor deposition (HFCVD). This difference may be due to the different dissociation mechanisms of the reactive gas in HCDC-PCVD, which is more efficient than that in HFCVD pointed out by P. Hartmann et al. [12], they indicated the high efficiency decomposition of the precursor gases of this method working with electron bombardment of a grounded substrate and a high gas temperature $(5000 \mathrm{~K})$ at relatively high pressure.

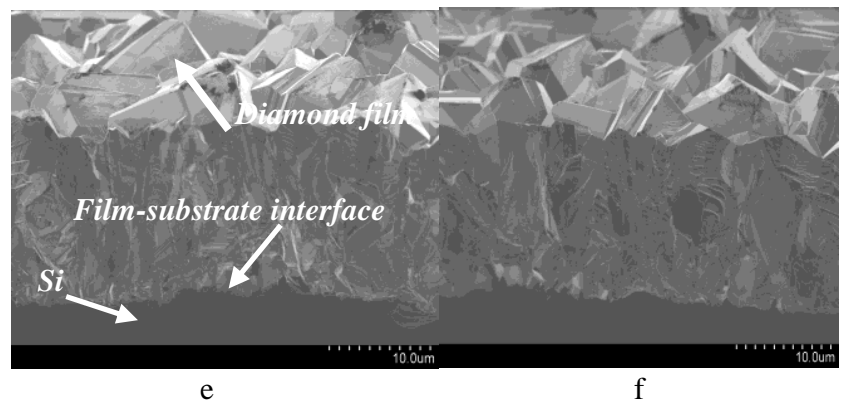

Fig. 2. Cross-sectional SEM images of sample e and $f$

The cross-sectional images of the BDD films were observed by SEM. Fig. 2 showed the typical crosssectional SEM images (sample e and f). The grains of BDD films were found to have wedge shapes with increasing size from bottom to top. All of the BDD films were without obvious fissures, assuring the requisite protection of the substrates. The thickness of about $16-22 \mu \mathrm{m}$ could be obtained from the cross-sectional SEM images. Hence, the average growth rates of $2-3 \mu \mathrm{m}^{-1}$ could be deduced.

Raman spectra of all the samples of BDD films grown with varied $\mathrm{B}\left(\mathrm{OCH}_{3}\right)_{3}$ flow rates were shown in Fig. 3 . There was a pointed peak at approximately $1332 \mathrm{~cm}^{-1}$ in each spectrum, corresponding to the first-order Raman curve of the diamond [4]. The peak was a symmetric Lorentzian at low boron level, but when the impurity concentration increased, the curve gradually and distinctly transformed into an asymmetric Fano-like line shape [5] with an increase on one side of the curve and a decrease of the other [13]. It is generally accepted that the asymmetry is induced by quantum interference between the continuum of electronic states induced by the incorporation of the boron dopant and the zone-centre Raman-active optical phonon. The interference turned up obviously when the boron dopant amount exceeds a critical level to achieve metallic conductivity on the boron impurity band, which transforms from broadened impurity band to continuum states composed of excited acceptor and valence band states [14, 15]. 


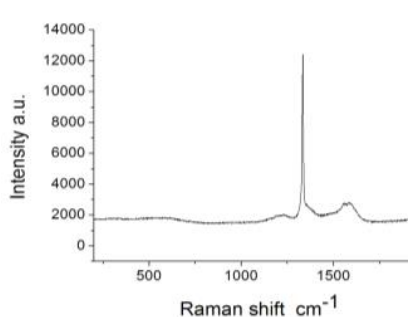

a

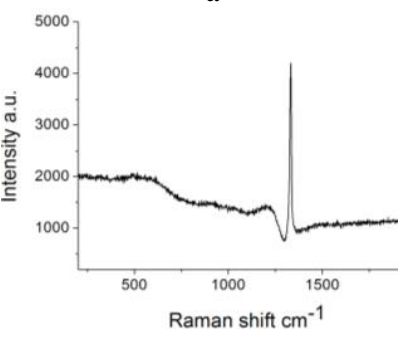

c

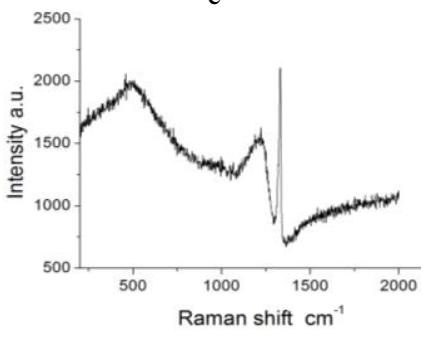

e

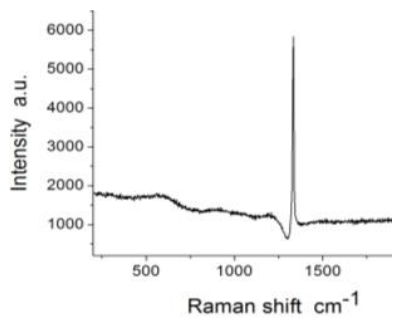

b

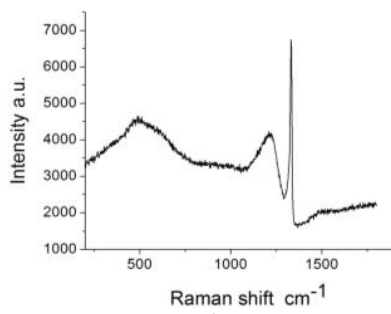

d

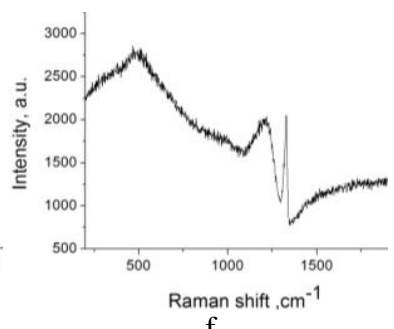

Fig. 3. Raman spectra of BDD films deposited at different $\mathrm{B}\left(\mathrm{OCH}_{3}\right)_{3}$ gas flow rate: $\mathrm{a}-0 \mathrm{sccm} ; \mathrm{b}-1 \mathrm{sccm}$; c -2 sccm; d -5 sccm; e-10 sccm; f-20 sccm

As shown in Fig. $3 \mathrm{~b}-\mathrm{f}$, the change in the profile of one phonon band eventually became significant with increasing boron concentration, broadening and decreasing intensity while gradually shifting to a lower wavenumber, as indicated in Table 2. Similar phenomenon had also been observed by R.J. Zhang et al. [10], they explained that the downshift of the zone-center phonon line at $1332 \mathrm{~cm}^{-1}$ may be caused by the uncertainty of the wavevector owing to increasing boron concentration in the diamond films. For diamond crystals with dense impurity, the Raman spectrum was dominated by phonons near the zone boundary, resulted in the density of the zone center mode at $1332 \mathrm{~cm}^{-1}$ is decreased with B dopant increased.

Additionally, two broad peaks appeared at $\sim 500 \mathrm{~cm}^{-1}$ and $\sim 1210 \mathrm{~cm}^{-1}$ which were first reported as indicators of an epitaxial layer of diamond [16] and then recognized [5] as polycrystalline boron-doped films. The origin of both peaks was undetermined, but their locations roughly correspond with two maxima states of the phonon density. They might be associated with the relaxation of the wavevector selection rules and related to the total amount of boron incorporated in the lattice, rather than the hole density [17]. It was reported [18] that the $500 \mathrm{~cm}^{-1}$ band originated from local vibrational modes of boron pairs, which caused a certain degree of distortion around these isolated defects in the diamond lattice. Both of the broad bands at $\sim 500 \mathrm{~cm}^{-1}$ and $\sim 1210 \mathrm{~cm}^{-1}$ strengthened with increasing boron concentration and dominated the curve at high boron content. Table 2 summarizes the features and tendencies of the gradual alteration of the reported peaks. The Raman results also indicated the presence of a weak $G$ band at $1585 \mathrm{~cm}^{-1}$, which was assigned to crystalline graphite impurities likely located at the grain boundaries.

Table 2. The Raman peak position and boron content deduced from $\mathrm{B}_{2}$ peak (fit of the peak by a Lorentzian component)

\begin{tabular}{|c|c|c|c|c|}
\hline sample & $\begin{array}{c}\text { dia.Peak, } \\
\mathrm{cm}^{-1}\end{array}$ & $\begin{array}{c}\mathrm{B}_{1} \text { peak, } \\
\mathrm{cm}^{-1}\end{array}$ & $\begin{array}{c}\mathrm{B}_{2} \text { peak, } \\
\mathrm{cm}^{-1}\end{array}$ & $\begin{array}{c}\text { [B] content, } \\
\mathrm{cm}^{-3}\end{array}$ \\
\hline $\mathrm{a}$ & 1334.11 & - & - & - \\
\hline $\mathrm{b}$ & 1332.57 & 1210.31 & 561.076 & $1.75 \times 10^{19}$ \\
\hline $\mathrm{c}$ & 1332.57 & 1194.71 & 513.871 & $1.63 \times 10^{20}$ \\
\hline $\mathrm{d}$ & 1331.80 & 1209.54 & 487.633 & $6.68 \times 10^{20}$ \\
\hline $\mathrm{e}$ & 1331.03 & 1222.78 & 457.91 & $2.40 \times 10^{21}$ \\
\hline $\mathrm{f}$ & 1329.50 & 1218.1 & 468.111 & $1.47 \times 10^{21}$ \\
\hline
\end{tabular}

However, the peak disappeared with the addition of boron in the films, implying that the incorporation of boron into the lattice structure of diamond may restrain the graphite forming thus lead to the quality of films improved. The Raman features were approximate with the results of P.W. May et al. [4], but they argued that the disappearance of the $\mathrm{G}$ band did not imply that there was less graphite in these films, only that the $G$ band signal was hidden beneath those from the other nearby features.

The B dopant concentration in the films was estimated by using the relationship between the boron concentration and the wavenumber of the Lorentzian component of the $500 \mathrm{~cm}^{-1}$ peak [15] as follows:

$[B] / \mathrm{cm}^{-3}=8.44 \times 10^{30} \exp (-0.048 \omega)$,

where the wavenumber position of the peak $\omega$ is in $\mathrm{cm}^{-1}$ and $[\mathrm{B}]$, the boron concentration, falls in the range of $2 \times 10^{20} \sim 1 \times 10^{22} \mathrm{~cm}^{-3}$.

Table 2 lists the doping contents of the BDD films, estimated by the relationship provided in Eq. 1. There were $1.75 \times 10^{19} \mathrm{~cm}^{-3}, \quad 1.63 \times 10^{20} \mathrm{~cm}^{-3}, \quad 6.68 \times 10^{20} \mathrm{~cm}^{-3}$, $2.40 \times 10^{21} \mathrm{~cm}^{-3}, 1.47 \times 10^{21} \mathrm{~cm}^{-3}$ when the B flux was set to $1 \mathrm{sccm}, 2 \mathrm{sccm}, 5 \mathrm{sccm}, 10 \mathrm{sccm}$, and $20 \mathrm{sccm}$, respectively. Results clearly demonstrate that the $\mathrm{B}$ content of the films were initially increased with B flux in the feeding gas, but when the flux ascended to $20 \mathrm{sccm}$, the B content decreased; this may be due to the dropping in plasma temperature with increasing $\mathrm{B}\left(\mathrm{OCH}_{3}\right)_{3}$ flow rate.

\section{CONCLUSIONS}

Boron-doped diamond (BDD) films were grown using hot cathode direct current plasma chemical vapor deposition (HCDC-PCVD) with a $\mathrm{CH}_{4} / \mathrm{H}_{2} / \mathrm{B}\left(\mathrm{OCH}_{3}\right)_{3}$ gas mixture with flux varying from $4 / 200 / 1 \mathrm{sccm}$ to $4 / 200 / 20 \mathrm{sccm}$. The results of SEM and Raman analysis indicated that the flow rate of $\mathrm{B}\left(\mathrm{OCH}_{3}\right)_{3}$ had marked effects on the growth characteristics of the produced boron-doped diamond films. SEM images manifested twinning bands within the grains intersecting with the surface. The grain facets gradually evolved with increasing boron flow rates into symmetrical and smooth structures. The primary grain size ranged from $2 \mu \mathrm{m}$ to $5 \mu \mathrm{m}$ for each sample. The thickness of about $16 \sim 22 \mu \mathrm{m}$ could be obtained from the cross-sectional SEM images and the average growth rates of $2 \sim 3 \mu \mathrm{m}^{-1}$ could be deduced. Raman spectra of the all samples of BDD films grown with varied $\mathrm{B}\left(\mathrm{OCH}_{3}\right)_{3}$ flow rates manifested properties as 
asymmetric Fano-like line shape diamond peak and two broad bands appeared at $\sim 500 \mathrm{~cm}^{-1}$ and $\sim 1210 \mathrm{~cm}^{-1}$, which related to the total amount of boron incorporated in the lattice. The doping levels in the films were mathematically estimated with a Raman shift wavenumber in the $\sim 500 \mathrm{~cm}^{-1}$ band. Results demonstrated that the $\mathrm{B}$ content in the films varied, indicating amounts of $1.75 \times 10^{19} \mathrm{~cm}^{-3}, \quad 1.63 \times 10^{20} \mathrm{~cm}^{-3}, \quad 6.68 \times 10^{20} \mathrm{~cm}^{-3}$, $2.4 \times 10^{21} \mathrm{~cm}^{-3}$, and $1.47 \times 10^{21} \mathrm{~cm}^{-3}$ when the $\mathrm{B}\left(\mathrm{OCH}_{3}\right)_{3}$ gas flow rate varied at $1 \mathrm{sccm}, 2 \mathrm{sccm}, 5 \mathrm{sccm}, 10 \mathrm{sccm}$ and $20 \mathrm{sccm}$, respectively.

\section{Acknowledgments}

This research was supported by the National Nature Science Foundation of China (Project 51262007) and the Nature Science Foundation of Hainan Province (Project 20165196).

\section{REFERENCES}

1. Iniesta, J., Michaud, P.-A., Panizza, M., Cerisola, G., Aldaz, A., Comninellis, Ch. Electrochemical Oxidation of Phenol at Boron-doped Diamond Electrode Electrochimica Acta 46 2001: pp. 3573-3578.

2. Silva, E.L., Neto, M.A., Fernandes, A.J.S., Bastos, A.C., Silva, R.F., Zheludkevich, M.L., Oliveira, F.J. Fast Coating of Ultramicroelectrodes with Boron-doped Nanocrystalline Diamond Diamond and Related Materials 19 2010: pp. $1330-1335$.

3. Ushizawa, K., Watanabe, K., Ando, T., Sakaguchi, I., Nishitani-Gamo, M., Sato, Y., Kanda, H. Boron Concentration Dependence of Raman Spectra on $\{100\}$ and \{111\} Facets of B-doped CVD Diamond Diamond and Related Materials 7 1998: pp. 1719-1722. http://dx.doi.org/10.1016/S0925-9635(98)00296-9

4. May, P.-W., Ludlow, W.-J., Hannaway, M., Heard, P.-J., Smith, J.-A., Rosser, K.-N. Raman and Conductivity Studies of Boron-doped Microcrystalline Diamond, Facetted Nanocrystalline Diamond and Cauliflower Diamond Films Diamond and Related Materials 17 2008: pp. 105-117. http://dx.doi.org/10.1016/j.diamond.2007.11.005

5. Zuzana, V.-Z., Otakar, F., Vaclav, P., Hana, T., Jiri, V., Milos, N., Ladislav, K. Electrochemistry and in Situ Raman Spectroelectrochemistry of Low and High Quality Boron Doped Diamond Layers in Aqueous Electrolyte Solution Electrochimica Acta 87 2013: pp. 518-525.

6. Baldan, M.R., Azevedo, A.F., Couto, A.B., Ferreira, N.G. Cathodic and Anodic Pre-treated Boron Doped Diamond with Different $\mathrm{sp}^{2}$ Content: Morphological, Structural and Impedance Spectroscopy Characterizations Vournal of Physics and Chemistry of Solids 74 2013: pp.1830-1835.

7. Feng, Y.-J., Lu, J.-G., Liu, J.-F., Gao, N., Peng, H.-Y., Chen, Y.-Q. Influence of Boron Concentration on Growth
Characteristic and Electro-catalytic Performance of Borondoped Diamond Electrodes Prepared by Direct Current Plasma Chemical Vapor Deposition Applied Surface Science 257 2011: pp. 3433-3439.

8. Liu, T., Raabe, D., Mão, W.-M. A Review of Crystallographic Textures in Chemical Vapor-Deposited Diamond Films Frontier of Materials Science 4 2010: pp. $1-16$.

9. Bartsch, K., Waidmann, S., Arnold, B., Oswald, S., Schlafer, D., Leonhardt, A., Summchen, L. Deposition of Undoped and Doped Textured Diamond Layers Thin Solid Films 377 2000: pp. 188-192. http://dx.doi.org/10.1016/S0040-6090(00)01275-X

10. Zhang, R.J., Lee, S.T., Lam, Y.W. Characterization of Heavily Boron-doped Diamond films Diamond and Related Materials 5 1996: pp. 1288-1294. http://dx.doi.org/10.1016/0925-9635(96)00539-0

11. Goncalves, J.A.N., Sandonato, G.M., Iha, K. Characterization of Boron Doped CVD Diamond by Raman Spectroscopy and X-ray Diffractometry Diamond and Related Materials 11 2002: pp. 1578-1583.

12. Hartmann, P., Haubner, R., Lux, B. Deposition of Thick Diamond Films by Pulsed D.C. Glow Discharge CVD Diamond and Related Materials 5 1996: pp 850-865. http://dx.doi.org/10.1016/0925-9635(95)00369-X

13. Matsushima, J.T., Silva, W.M., Azevedo, A.F., Baldan, M.R., Ferreira, N.G. The Influence of Boron Content on Electroanalytical Detection of Nitrate using BDD Electrodes Applied Surface Science 256 2009: pp. $757-762$. http://dx.doi.org/10.1016/j.apsusc.2009.08.055

14. Pruvost, F., Deneuville, A. Analysis of the Fano in Diamond Diamond and Related Materials 10 2001: pp. $531-535$ http://dx.doi.org/10.1016/S0925-9635(00)00378-2

15. Joel, W.A., Walukiewicz,W., Landstrass, I. Fano Interference of the Raman Phonon in Heavily Boron-doped Diamond Films Grown by Chemical Vapor Deposition Applied Physics Letters 66 (5) 1995: pp. 616-618.

16. Gheeraert, E., Gonon, P., Deneuville, A., Abello, L., Lucazeau, G. Effect of Boron Incorporation on the Quality of MPCVD Diamond Films Diamond and Related Materials 2 1993: pp. 742-748. http://dx.doi.org/10.1016/0925-9635(93)90215-N

17. Bernard, M., Deneuville, A., Muret, P. Non-destructive Determination of the Boron Concentration of Heavily Doped Metallic Diamond Thin Films from Raman Spectroscopy Diamond and Related Materials 13 2004: pp. 282-286.

18. Goss, J.-P., Briddon, P.-R. Theory of Boron Aggregates in Diamond: First-principles Calculations Physical Review B 73 2006: pp. 085204-085208. http://dx.doi.org/10.1103/PhysRevB.73.085204 